JAMP: Jurnal Adminitrasi dan Manajemen Pendidikan

Volume 4 Nomor 2 Juni 2021, Hal : 115 - 120

Tersedia Online di http://journal2.um.ac.id/index.php/jamp/

ISSN 2615-8574 (online)

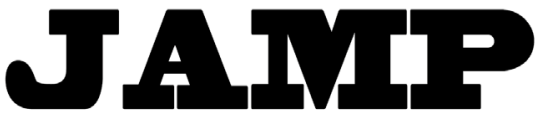

\title{
EVALUASI KINERJA GURU BIOLOGI DENGAN MODEL KERANGKA PENGAJARAN DANIELSON
}

\author{
Erfy Melany Lalupanda ${ }^{1}$ \\ Vidriana Oktoviana Bano ${ }^{2}$
}

\author{
Universitas Kristen Wira Wacana Sumba Jln. R. Suprapto No. 35, Sumba Timur- NTT \\ Email: erfy@unkriswina.ac.id No.HP: 085253388475
}

\begin{abstract}
The purpose of this study was to evaluate the performance of Biology teachers in East Sumba Regency. This research is an evaluation research that uses a quantitative approach. The total population of the study was 44 biology teachers, with a sample of 20 teachers. The data collection technique used a questionnaire based on the teaching framework rubric by Charlotte Danielson. The data analysis technique used quantitative descriptive. The results of research in the domain of learning preparation, $45 \%$ of teachers are in the Basic category or good enough. In the domain of classroom environmental management, $70 \%$ of teachers are in the Proficient or good category. In the domain of the implementation of learning, 50\% of the teachers were categorized as Basic or quite good. In the domain of professional responsibility, $55 \%$ of teachers are in the Basic category. These results indicate that the performance of Biology teachers in East Sumba Regency needs to be improved, especially in the domains of learning preparation, learning implementation and professionalism.
\end{abstract}

Keywords: Performance Evaluation; Biology Teacher; Charlotte Danielson.

\begin{abstract}
Abstrak: Tujuan penelitian ini adalah untuk mengevaluasi kinerja guru Biologi di Kabupaten Sumba Timur. Penelitian ini merupakan penelitian evaluasi yang menggunakan pendekatan kuantitatif. Jumlah populasi penelitian adalah 44 orang guru Biologi, dengan sampel yang diteliti 20 orang guru. Teknik pengambilan data menggunakan kuesioner berdasarkan Rubrik kerangka pengajaran oleh Charlotte Danielson. Teknik analisis data menggunakan deskriptif kuantitatif. Hasil penelitian pada domain persiapan, $45 \%$ guru berada pada kategori Basic atau cukup baik. Pada domain pengelolaan lingkungan kelas, $70 \%$ guru berada pada kategori Proficient atau baik. Pada domain pengajaran, 50\% guru berkategori Basic atau cukup baik. Pada Domain Tanggungjawab profesional 55\% guru berkategori Basic. Hasil ini menunjukkan bahwa kinerja guru Biologi Kabupaten Sumba Timur perlu untuk ditingkatkan khususnya pada domain persiapan pembelajaran, pengajaran dan profesionalitas.
\end{abstract}

Kata kunci: Evaluasi Kinerja; Guru Biologi; Model Charlotte Danielson.

Dewasa ini, kemajuan dan kemutkahiran teknologi merupakan salah satu ukuran mutu sistem pendidikan negara-negara di dunia. Kemajuan dalam penggunaan teknologi sangat ditentukan oleh kehadiran ilmu sains. Ilmu sains khususnya Biologi menempati posisi yang strategis dalam sistem pendidikan. Melalui pembelajaran Biologi dapat dihasilkan lulusan yang kritis, kreatif, inovatif dan kompetitif untuk menjawab tantangan di era ini (Sudarisman, 2015). Biologi bukanlah ilmu pengetahuan yang statis, tetapi merupakan ilmu pengetahuan dinamis yang terus mengalami perkembangan. Sehingga di era persaingan global saat ini peningkatan mutu pendidikan pada pembelajaran Biologi di sekolah menjadi hal yang sangat penting dan urgen.

Peningkatan mutu pendidikan mata pelajaran Biologi di Indonesia telah di lakukan melalui perubahan struktur kurikulum yang meliputi konten dan metode pembelajaran sesuai dengan perkembangan zaman. Namun, sebaik apa pun struktur kurikulum, tanpa hadirnya seorang guru sebagai agen implementasi, 
mustahil mutu pendidikan khususnya dalam pembelajaran Biologi akan meningkat. Sebagai salah satu alternatif untuk mengurai hal tersebut perlu adanya pengaturan jam mengajar. Adipratama, dkk. (2018) menyatakan bahwa, pengaturan jam mengajar yang baik akan berdampak pada pengajaran yang efektif dan efisien, begitu juga sebaliknya.

Berdasarkan data yang diperoleh dari Pusat Penilaian Pendidikan Kementerian Pendidikan Dan Kebudayaan tahun 2019, rata-rata nilai Ujian Nasional (UN) pelajaran Biologi di Kabupaten Sumba Timur, Provinsi NTT adalah 39,9. Jika dibandingkan dengan nilai rata-rata UN Biologi di 3 Kabupaten lain yang ada di pulau Sumba yaitu Sumba Tengah $(42,1)$, Sumba Barat $(44,2)$ dan Sumba barat daya $(40,1)$, nilai UN Biologi di Kabupaten Sumba Timur adalah yang paling rendah. Hal ini cukup memperihatikan dan sangat membutuhkan perhatian dari semua kalangan.

Salah satu langkah yang dapat di lakukan pemerintah daerah untuk mengidentifikasi penyebab permasalahan ini, yaitu dengan melakukan evaluasi kinerja guru Biologi. Evaluasi kinerja guru adalah cara yang dilakukan untuk mendapatkan informasi terkait keefektifan seorang guru dalam melaksanakan tugas dan tanggungjawabnya dalam meningkatkan mutu pembelajaran.

Evaluasi kinerja sangat dibutuhkan oleh seorang guru dalam pengembangan profesionalisme berkelanjutan, karena hasil evaluasi akan memberikan umpan balik yang adil dan bermanfaat bagi guru. Hasil yang diperoleh dapat menjadi informasi yang dapat digunakan guru sebagai dasar dalam perbaikan, peningkatan dan pengembangan profesionalisme guru. Selanjutnya data dari evaluasi guru dapat memberikan gambaran yang jelas bagi peningkatan mutu pendidikan.

Kinerja guru perlu untuk dievaluasi secara periodik dan berkelanjutan menggunakan suatu instrumen penilain kinerja yang komprehensif. Instrumen penilaian yang komprehensif sangat dibutuhkan untuk mencapai tujuan peningkatan kinerja guru.

Salah satu model evaluasi kinerja yang efektif dalam menilai kinerja guru adalah model evaluasi Charlotte Danielson. Model evaluasi ini mengukur kinerja guru berdasarkan 4 domain yaitu (1) persiapan; (2) pengelolaan lingkungan kelas; (3) pengajaran; (4) profesionalitas (Lalupanda, et al., 2019).

Model kerangka pengajaran oleh Charlotte Danielson memiliki kerangka kerja yang memastikan standar praktik yang tinggi, mencontohkan kompleksitas mengajar, menawarkan peta pengajaran bagi profesi guru, dan memberikan kesamaan bahasa untuk memungkinkan wacana yang jelas terkait dengan kinerja guru (Phillips et al., 2014). Model ini menjelaskan betapa pentingnya melakukan pembimbingan dan pengembangan kinerja guru melalui rubrik penilaian kinerja yang menjadi pedoman bagi para guru, kepala sekolah dan pengawas untuk meningkatkan dan mengembangkan profesionalisme guru (Erasmus and Vermeulen, 2015).

Berdasarkan permasalahan diatas maka peneliti melakukan penelitian Evaluasi Kinerja Guru Biologi yang berada Kabupaten Sumba Timur dengan rubrik kerangka pengajaran Danielson. Tujuan penelitian ini adalah memberikan gambaran menyeluruh kinerja guru Biologi di Kabupaten Sumba Timur. Hasil penelitian ini diharapkan juga dapat menemukan letak kelemahan dan kekurangan proses pembelajaran Biologi selama ini, sehingga dapat diberi rekomendasi berupa perbaikan dan peningkatan kinerja guru.

\section{METODE}

Jenis penelitian yang digunakan adalah penelitian evaluasi dengan pendekatan kuantitatif. Penelitian di lakukan pada 10 SMA yang berada di Kabupaten Sumba Timur. Sampel penelitian adalah 20 orang guru Biologi. Teknik pengambilan data menggunakan kuesioner yang disusun dalam bentuk rubrik kerangka pengajaran guru yang dikembangkan oleh Danielson. Teknik analisis data yang digunakan adalah deskriptif kuantitatif. 


\section{HASIL}

Hasil pelaksanaan penelitian evaluasi kinerja Guru Biologi disajikan pada tabel berikut. Tabel 1. Kinerja Guru Biologi di Kabupaten Sumba Timur.

\begin{tabular}{ccccc}
\hline \multirow{2}{*}{ No } & \multicolumn{4}{c}{ Domain } \\
\hline & Persiapan & Pengelolaan Kelas & Pengajaran & Profesionalitas \\
\hline 1 & 4 & 3 & 4 & 4 \\
2 & 3 & 2 & 3 & 2 \\
3 & 3 & 2 & 3 & 2 \\
4 & 3 & 2 & 2 & 2 \\
5 & 2 & 2 & 2 & 2 \\
6 & 4 & 3 & 3 & 3 \\
7 & 4 & 3 & 4 & 3 \\
8 & 4 & 3 & 4 & 3 \\
9 & 2 & 2 & 2 & 3 \\
10 & 4 & 3 & 3 & 4 \\
11 & 4 & 3 & 3 & 4 \\
12 & 2 & 3 & 2 & 2 \\
13 & 2 & 3 & 2 & 2 \\
14 & 2 & 3 & 2 & 2 \\
15 & 2 & 2 & 2 & 2 \\
16 & 2 & 3 & 2 & 2 \\
17 & 2 & 3 & 2 & 2 \\
18 & 2 & 3 & 2 & 2 \\
19 & 4 & 3 & 4 & 3 \\
20 & 3 & 3 & 3 & 3 \\
\hline & 58 & 54 & 54 & 52 \\
\hline
\end{tabular}

Keterangan Kategori

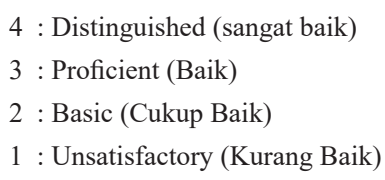

Berdasarkan Tabel 1 dapat diketahui bahwa hasil evaluasi Domain Persiapan dan Perencanaan pembelajaran, dari 20 orang guru biologi Kabupaten Sumba Timur hanya 35\% yang yang berada pada kategori Distinguished, sedangkan pada kategori Proficient hanya 20\%, dan 45\% guru berada pada kategori Basic. Sehingga dapat disimpulkan bahwa guru Biologi di Kabupaten Sumba Timur berada pada kategori Basic atau cukup baik pada domain persiapan pembelajaran

Pada domain pengelolaan lingkungan kelas, 70\% guru berkategori Proficient, dan 30\% berkategori Basic dalam mengelolah kelas. Berdasarkan hasil tersebut dapat disimpulkan bahwa pada domain pengelolaan lingkungan kelas, guru Biologi di Kabupaten Sumba Timur, berada pada kategori Proficient atau baik.

Pada domain pengajaran, 20\% guru berkategori Distinguished, 30\% guru berkategori Proficient, dan 50\% guru berkategori Basic. Berdasarkan hasil tersebut dapat disimpulkan bahwa pada tersebut, guru Biologi berkategori Basic atau cukup baik.

Pada domain profesionalitas, hanya $15 \%$ guru berkategori Distinguished, sedangkan pada kategori Proficient hanya 30\% guru dan 55\% guru berkategori Basic. Hasil tersebut menunjukkan bahwa domain profesionalitas, guru Biologi berkategori Basic atau cukup baik. 


\section{PEMBAHASAN}

Hasil penelitian ini menunjukkan bahwa pada tahap persiapan hampir sebagian besar guru Biologi di Kabupaten Sumba Timur belum mempersiapkan dan merencanakan pembelajaran dengan sangat baik. Banyak faktor yang mempengaruhi hasil tersebut. Salah satunya, berdasarkan hasil penelitian di peroleh informasi bahwa guru yang berada pada kategori Distinguished dan Proficient adalah guru senior, PNS, dan sudah bersertifikasi. Sedangkan guru yang berada pada kategori Basic merupakan guru muda yang masih berstatus honorer, sehingga masih membutuhkan banyak bimbingan dan pelatihan dalam membuat perangkat pembelajaran. Padahal persiapan dan perencanaan pembelajaran merupakan acuan dan panduan utama bagi guru dalam melaksanakan proses pembelajaran.

Persiapan dan perencanaan pembelajaran sangat menentukan arah dan kualitas pembelajaran. Pencapaian tujuan kurikulum tidak hanya mengejar kecukupan, namun harus mencapai atau melampaui standar yang ditetapkan. Apalagi untuk pembelajaran Biologi dewasa ini yang selalu mengalami perkembangan dengan adanya temuan-temuan baru. Sehingga guru Biologi dituntut untuk mampu merencanakan pembelajaran dengan sangat baik untuk mempersiapkan siswa menghadapi revolusi industri 4.0. Sejalan dengan itu Viviano (2012) menyatakan bahwa dalam membimbing siswa, guru harus memiliki kendali atas mata pelajaran yang diajarkan. Guru harus mengetahui konsep dan keterampilan mana yang penting untuk dimiliki siswa. Guru yang berhasil memahami hubungan internal dalam disiplin ilmu, akan mampu mengetahui konsep dan keterampilan mana yang akan ditanamkan pada siswa. Namun, sekedar pengetahuan saja tidak cukup, guru harus terbiasa dengan pendekatan pedagogis yang paling cocok untuk setiap disiplin ilmu yang diajarkan.

Pada tahap pengelolaan lingkungan kelas, hampir semua guru mampu mengelolah kelas dengan baik, meskipun belum mencapai nilai tertinggi, yaitu sangat baik. Namun hasil ini menunjukkan bahwa guru Biologi di Kabupaten Sumba Timur sudah mampu menciptakan hubungan yang baik antara guru dengan siswa atau siswa bersama rekan-rekannya, guru mampu menciptakan kondisi belajar yang aman dan nyaman dalam kelas, membuat aturan dalam kelas, serta memperhatikan tingkah laku peserta didik. Kondisi lingkungan kelas yang kondusif dan strategis membuat peserta didik merasa aman dan nyaman dalam mengikuti proses pembelajaran dalam kelas.

Selain itu proses pembelajaran Biologi tidak selamanya hanya dilakukan di dalam kelas, tetapi juga dapat dilakukan di laboratorium. Sehingga penting bagi guru Biologi untuk memperhatikan dan mengkondisikan lingkungan laboratorium, agar tidak menjadi tempat belajar yang berbahaya bagi siswa. Menurut Duban (2019), guru sains harus mampu mengelolah laboratorium agar menjadi tempat belajar yang aman bagi siswa. Laboratorium sains berperan sangat penting untuk membangun partisipasi aktif siswa dalam proses pembelajaran. Praktik laboratorium memainkan peran sentral untuk mengisi kesenjangan antara teori dan praktik. Kegiatan praktikum mendefinisikan konsep ilmu secara lebih komprehensif dengan cara yang bermakna.

Pada tahap pengajaran, sebagian besar guru masih menunjukkan kinerja yang cukup baik. Data ini juga menunjukkan bahwa ada keselarasan antara kemampuan menyusun persiapan dan perencanaan pembelajaran dengan kemampuan melaksanakan proses pembelajaran di kelas. Terbukti dengan hasil pada Tabel 1 guru yang merencanakan pembelajaran dengan baik adalah guru yang mampu melaksanakan pembelajaran dengan baik. Selain itu berdasarkan hasil rubrik, kelemahan guru dalam tahap ini adalah belum melibatkan partisipasi aktif siswa secara penuh dalam pembelajaran. Guru hanya membuat siswa aktif saat proses tanya jawab. Pola pembelajaran yang demikian menurut Pane \& Dasopang (2017) merupakan pola pembelajaran transmisif, dimana siswa hanya menerima pengetahuan dari guru, dan belum mengkonstruksi struktur pengetahuan sendiri.

Proses pembelajaran dilaksanakan untuk mencapai tujuan yang sudah direncanakan. Dalam proses ini, guru harus mampu membangun komunikasi yang akurat dengan peserta didik, mampu menggunakan berdiskusi dengan peserta didik sesuai dengan tingkatan perkembangan belajar pserta didik, memberi penugasan baik secara individu maupun berkelompok, menilai hasil belajar menggunakan rubrik yang akurat, serta cepat tanggap terhadap kebutuhan siswa. Kemapuan guru dalam melaksanakan proses pembelajaran menunjukkan kemampuan para guru dalam menggunakan pendekatan pembelajaran, 
model pembelajaran, strategi pembelajaran, dan metode yang tepat. Ariyanti, dkk. (2020) hasil penelitiannya menyebutkan bahwa salah satu permasalahan yang harus diselesaikan terlebih dahulu yaitu guru mengajar tidak sesuai.

Pada tahap pengembangan tanggungjawab profesional juga menunjukkan bahwa sebagian besar guru belum mampu mengembangkan profesionalisme sebagai seorang pendidik dalam hal melakukan intropeksi dan refleksi terhadap proses pembelajaran yang telah dilaksanakan, membuat jurnal pembelajaran terkait kemajuan belajar peserta didik, membangun komunikasi dengan orang tua peserta didik, dan berpartisipasi aktif dalam kelompok profesional. Tujuan seorang guru harus memiliki tanggungjawab profesional adalah untuk dapat mengaktualisasi diri sebagai seorang pendidik profesional. (Pharis et al., 2018) meyatakan bahwa guru dapat merefleksikan pengajaran, menganalisis, dan membuat keputusan profesional dalam praktik mengajar melalui melalui diskusi dengan rekan sejawat. kolegial, memeriksa pekerjaan siswa, dan berpartisipasi dalam komunitas profesional seperti KKG dan MGMP. Selain itu, diperlukan pula sosok kepala sekolah yang menerapkan kepemimpinan pembelajaran. Hal ini sebagaimana yang disampaikan oleh Puspitaningtyas, dkk. (2019) bahwa melalui kepemimpinan pembelajaran diharapkan dapat meningkatkan mutu profesionalisme guru, meningkatkan motivasi, inovasi, kreativitas guru untuk tujuan utama pencapaian prestasi peserta didik

Hasil penelitian terdahulu yang dilakukan oleh Oktra, et.al (2018) menunjukan bahwa pada perencanaan, pelaksanaan, dan evaluasi pembelajaran guru berada pada kategori cukup sampai baik. Selain itu, hasil ini juga didukung dengan penelitian yang dilakukan oleh Lalupanda (2019). Penelitian tersebut menunjukkan bahwa pada domain persiapan pembelajaran berada dalam kategori baik, pengelolaan linkungan kelas cukup baik, pelaksanaan pembelajaran berkategori baik, dan profesionalitas cukup baik. Menurut Rizal (2019), seorang guru yang berkinerja baik bahkan sangat baik adalah guru yang mampu memperoleh kategori yang tinggi pada semua komponen penilaian kinerja.

\section{SIMPULAN DAN SARAN}

\section{Simpulan}

Kinerja guru Biologi di Kabupaten Sumba Timur perlu untuk diperbaiki dan ditingkatkan, agar menghasilkan pembelajaran Biologi yang bermutu. Hasil penelitian ini dapat menjadi tolak ukur bagi pihak berwenang bidang pendidikan di Kabupaten Sumba Timur dalam memperbaiki dan meningkatkan kinerja guru Biologi.

\section{Saran}

Saran penulis bagi peneliti lain yang melakukan penelitian lanjutan terkait kinerja guru Biologi di Kabupaten Sumba Timur adalah agar dapat mengakaji lebih mendalam terkait faktor-faktor yang mempengaruhi kinerja guru Biologi di Kabupaten Sumba Timur.

\section{DAFTAR RUJUKAN}

Adipratama, Z., Sumarsono, R. B. dan Ulfatin, N. 2018. Manajemen Kurikulum Terpadu di Sekolah Alam Berciri Khas Islam. JAMP: Jurnal Administrasi dan Manajemen Pendidikan. Volume 1. Nomor 3. September 2018. http://journal2.um.ac.id/index.php/jamp/article/view/5046/2755

Ariyanti, N. S., Adha, M. A., Sumarsono, R. B. and Sultoni. 2020. Strategy to Determine the Priority of Teachers' Quality Problem Using USG (Urgency, Seriousness, Growth) Matrix. International Research-Based Education Journal. Volume 2 No 2. http://journal2.um.ac.id/index.php/irbej

Duban, N., Aydoğdu, B. and Yüksel, A. (2019) 'Classroom teachers' opinions on science laboratory practices', Universal Journal of Educational Research, 7(3). doi: 10.13189/ujer.2019.070317.

Erasmus, J. and Vermeulen, N. (2015) 'The use of Danielson's Framework in developing a new fieldwork training setting for 3rd year occupational therapy students from the University of the Western Cape', South African Journal of Occupational Therapy, 45(2). doi: 10.17159/2310-3833/2015/v45n2a11. 
Lalupanda, E. M., Sulasmono, B. S. and Iriani, A. (2019) 'Evaluasi Kinerja Guru SMA Bersertifikasi Dengan Model Charlotte Danielson Di SMA Negeri’, Kelola: Jurnal Manajemen Pendidikan, 6(1). doi: 10.24246/j. jk.2019.v6.i1.p11-24.

Oktra, D. A. and Aufa, M. (2018) 'Studi Evaluasi Kinerja Guru Kelas Mi Bersertifikasi Ijazah Non-Pgmi Terhadap Kompetensi Pedagogik Dan Profesional Di Kabupaten Magelang’, Pendas : Jurnal Ilmiah Pendidikan Dasar. doi: 10.23969/jp.v3i1.773.

Pane, A. and Dasopang, M. D. (2017) 'Belajar Dan Pembelajaran', Fitrah:Jurnal Kajian Ilmu-ilmu Keislaman, 3(2). doi: 10.24952/fitrah.v3i2.945.

Pharis, T. J. et al. (2018) 'Implementation of the Teacher Professional Growth and Effectiveness System in Rural Kentucky High Schools', International Journal of Education Policy and Leadership, 13(5). doi: 10.22230/ ijepl.2018v13n5a740.

Phillips, K., Balan, R., \& Manko, T. (2014) 'Teacher evaluation: Improving the process. ', Transformative Dialogues: Teaching and Learning Journal, 7(3).

Puspitaningtyas, I., Satria, R. Maisyaroh, Sumarsono, R.B. 2019. Implementasi Kepemimpinan Pembelajaran di Satuan Pendidikan. Seminar Nasional Revitalisasi Manajemen Pendidikan Anak Usia Dini (PAUD) di Era Revolusi Industri 4.0

http://conference.um.ac.id/index.php/apfip2/article/view/368

Rizal, R. (2019) 'Evaluasi Kinerja Guru IPA', MadrosatunA : Jurnal Pendidikan Guru Madrasah Ibtidaiyah, 2(2). doi: 10.47971/mjpgmi.v2i2.124.

Sudarisman, S. (2015) 'Memahami Hakikat Dan Karakteristik Pembelajaran Biologi Dalam Upaya Menjawab Tantangan Abad 21 Serta Optimalisasi Implementasi Kurikulum 2013', Florea: Jurnal Biologi dan Pembelajarannya, 2(1). doi: 10.25273/florea.v2i1.403.

Viviano, T. (2012) 'Charlotte Danielson or National Board Certification: A Comparison and Contrasting of Two Major National Frameworks for Teaching', Journal of Career and Technical Education, 27(2). doi: 10.21061/ jcte.v27i2.563. 